\title{
Bibliotecário 2.0: novos desafios na era da sociedade em rede
}

Mara Karoline Lins Teotônio ${ }^{1}$

RESUMO: Profissionais da informação precisam enfrentar as mudanças da sociedade em rede, principalmente a evolução entre a biblioteca 1.0 e a biblioteca 2.0. Este artigo explora a evolução entre a biblioteca 1.0 e a biblioteca 2.0 para discutir os desafios para os bibliotecários e as adaptações tecnológicas necessárias para trabalhar com a web 2.0

Palavras-chave: Web 2.0; Bibliotecário2.0; Profissionais da informação

Abstract: Information professionals need to deal with the changes of the networked society, especially the evolution between the library 1.0 and 2.0 library. This article explores the evolution between the library 1.0 and 2.0 library to discuss the challenges to the librarians and the technological adaptations necessary for working with web 2.0.

Keywords: Web 2.0; librarian 2.0; information professionals

\footnotetext{
${ }^{1}$ Bibliotecária da Biblioteca Central da Universidade de Brasília e mestranda no PPGCINF da Universidade de Brasília.
} 


\section{As Novas Tecnologias e o Bibliotecário}

Em pleno século XXI, as tecnologias da informação e comunicação estão cada vez mais presentes nas atividades tanto profissionais como rotineiras dos seres humanos. Essas tecnologias mudaram a nossa sociedade em maior ou menor grau. Castells (2005) acredita que a tecnologia da informação é a ferramenta principal para reestruturação socioeconômica, possibilitando a formação em rede e o maior dinamismo e flexibilidade.

A maneira como os indivíduos se organizam, trabalham ou mesmo se divertem é influenciada pela utilização das tecnologias, que deixam de ter papel de instrumento para assumir o papel de mediadoras entre informação e as necessidades informacionais de indivíduos e organizações (RIBEIRO ET AL, c2005).

Segundo Miranda (2000) "um dos principais indicadores do desenvolvimento na Sociedade da Informação é a penetrabilidade das tecnologias de informação na vida diária e no funcionamento e transformação da sociedade no todo".

Siqueira (2005) aponta as dez alavancas tecnológicas que mudaram a vida humana em todos os aspectos:

\begin{tabular}{|l|}
\hline $\begin{array}{l}\text { 1. Convergência - sinergia de } 3 \text { mundos (provedores da informação, } \\
\text { computadores e telecomunicações) }\end{array}$ \\
\hline 2. Microeletrônica \\
\hline 3. Computadores - a grande ferramenta \\
\hline 4. Software - a inteligência nos chips \\
\hline 5. Internet - bilhões na rede global \\
\hline 6. Wireless - o mundo sem fio \\
\hline 7. Fibras óticas \\
\hline 8. Mass storage - armazenamento trilhões de bits \\
\hline 9. Nanotecnologia - máquinas e robôs moleculares \\
\hline 10. Networking - tudo em rede
\end{tabular}


Dentre as tecnologias desenvolvidas a que mais vem causando impactos na sociedade é a criação da internet. Originalmente nascida em 1969, a partir da Arpanet, com o objetivo de preservar o conhecimento científico americano. Um marco que impulsionou a internet foi a criação do protocolo TCP-IP em 1973 por Vinton Cerf e Robert Kahn. Dessa forma foi possível a comunicação entre computadores de arquiteturas diferentes. Outro grande acontecimento foi a criação da hipermídia www (world wide web) no ano de 1990, desenvolvida por Tim Berners-Lee (SIQUEIRA, 2008). No Brasil, a internet foi implementada em 1995. A rede teve uma grande expansão desde seu início até os dias de hoje. Segundo levantamento da F/Nazca realizado semestralmente, o número de internautas brasileiros estava na faixa dos 81,3 milhões em 2010. De acordo com a pesquisa, desse total $60 \%$ mudaram a plataforma tradicional (TV e cinema) e passaram assistir e ouvir programas ou filmes via internet. Mas, apesar disso, 59\% dos internautas preferem ver notícias na televisão. Apenas, $22 \%$ da população brasileira costumam acessar a internet para consultar notícias e 51\% costumam acessar as seguintes redes sociais: Orkut, Twitter e Youtube.

A internet vem sofrendo mudanças de estrutura, e essas mudanças estão tornando-a mais interativa, isso permite a oferta de vários serviços de informação pela biblioteca e, de várias maneiras: por meio de blogs; oferta de repositórios especializados e outras facilidades (LINHAUS; OLIVEIRA, 2010).

O bibliotecário no contexto atual, em que a informação é insumo para o desenvolvimento, se vê desafiado com a nova era, onde a sociedade encontra-se cada vez mais conectada a internet e, rapidamente, dissemina e gera o conhecimento no âmbito competitivo de mercado, e internamente na sociedade.

Assim, estes profissionais não podem ignorar as mudanças eminentes, apesar de o impacto da tecnologia ser enfatizado, na verdade a tecnologia não pode ser vista separada do ser humano, pois,

[...] em vez de enfatizar o impacto da tecnologia, poderíamos igualmente pensar que as tecnologias são produtos de uma sociedade e de uma cultura [...], sua presença e uso em lugar e época determinados cristalizam relações de força sempre diferentes entre seres humanos (LÉVY, 2000, p.22-3). 
Com relação às profissões que foram influenciadas pela revolução tecnológica, tornando obsoletos seus conhecimentos ou mesmo tendo colocado em xeque a existência da mesma, essa evolução torna-se algo ameaçador. A aceleração das alterações tecnológicas é tão rápida que até mesmo aqueles mais antenados podem estar ultrapassados (LÉVY, 2000).

A seguir serão abordados alguns conceitos e características do bibliotecário 2.0, biblioteca 2.0 e da web 2.0 com o intuito de ampliar as discussões entre os profissionais da informação.

\section{Bibliotecário 2.0}

Santos (2002) constata que a Biblioteconomia passa por um momento de reflexão, uma necessidade de mudanças não só no currículo mas também nas bases elementares.

A difusão do uso das tecnologias a serviço da informação transpõe barreiras físicas e institucionais. $\mathrm{O}$ ato de conhecer os mecanismos virtuais existentes tornou-se natural tanto quanto saber a localização de um livro na estante da biblioteca e o uso da internet passou a ser um instrumento obrigatório de trabalho do bibliotecário (SILVA, 2005).

Um levantamento realizado na base de dados Library Literature Information Abstracts (Lisa) com o termo librarian 2.0 (em português: bibliotecário 2.0), recuperou cerca de quinze referências, sendo quatro destas resenhas de um mesmo livro. Isso se deve ao fato do termo ter aparecido pela primeira vez recentemente, em 2005, pela citação do vice-presidente de inovação da SirsiDynix Institute , Stephen Abram.

Dentre as ferramentas da web 2.0, as redes sociais ganharam importância, "como fenômeno emergente dos coletivos digitais, pois os usuários são consumidores e autores da informação e produtores de conhecimentos", rompendo, dessa maneira, com os papéis tradicionais de editores e bibliotecários, sendo até difícil encontrar diferenças entre alguns conteúdos na web, se estes seriam ou não produção editorial ou uma versão da web 2.0 (PASSARELLI, 2009).

O bibliotecário deve deter o conhecimento essencial das ferramentas principais da web 2.0 para divulgar os conteúdos de suas bibliotecas por meio desse mecanismo. 0 
profissional capaz de conhecer e dominar esses serviços pode se adaptar a outras áreas e serviços e, até mesmo obter melhor desempenho nas atividades (BRITO; SILVA, 2010).

As discussões a respeito do uso de ferramentas da web 2.0 em bibliotecas culminaram no surgimento da biblioteca 2.0 e, no que exatamente é uma biblioteca com essa denominação. Percebe-se uma mudança na maneira de se pensar em bibliotecas no contexto tecnológico atual, e principalmente a interação com os usuários. Além disso, com essa nova realidade emerge um novo perfil profissional para atender as necessidades tanto institucionais como as advindas do contexto externo, este profissional é encontrado na literatura com a denominação: o bibliotecário 2.0.

E como fica o profissional numa era onde provedores de informação como Google satisfazem as necessidades de informação dos usuários que antes usavam a biblioteca para esse fim? Na literatura são encontradas várias características que esse novo profissional deve ter, a seguir seguem algumas.

Laura Cohen em 2006 publicou no blog Library 2.0: an academic's perspective o Librarian's 2.0 Manifesto, que foi difundido e citado em vários artigos e também em outros blogs da área de biblioteconomia. Esse manifesto lista atitudes que o bibliotecário 2.0 deve ter, dentre elas: não temer os serviços do Google, reconhecer a mudança do universo informacional e modificar serviços com base na opinião de usuários.

Stephens (2006) publicou na OCLC online uma lista de seis características que o bibliotecário deve ter para obter êxito na era da web 2.0, a saber: planejar com o foco nos usuários, abraçar as ferramentas da web 2.0, controlar a tecnolust (significa dizer que o bibliotecário deve usar as tecnologias não por estarem em voga, mas pelo fato de serem úteis e testadas previamente para um propósito definido pela instituição), ser rápido na tomada de decisões, e estar antenado com as novas tendências tecnológicas. Além disso, os bibliotecários devem entender que o futuro das bibliotecas será guiado pelo fato de que seus usuários acessam, consomem e criam conteúdos.

King (2007) fez uma interessante reflexão sobre bibliotecários 2.0, a questão do autor não é ser ou não um tech geek (pessoa obcecada por tecnologia), e também não 
é o fato de dividir os profissionais por idade, em novos e velhos bibliotecários. King (2007) propõe um jogo de perguntas para descobrir se o profissional é ou não um bibliotecário 2.0: o profissional tem um trabalho numa biblioteca 2.0; mesmo que não tenha o título, o profissional implementa as tendências emergentes; não faz isso no seu trabalho, mas pessoalmente tem blog, um perfil no facebook, várias contas em programas de mensagens instantâneas e outros.

Abram (2008) afirma que o bibliotecário 2.0 é o guru da era da informação e relaciona uma série de habilidades e necessidades desse profissional, dentre elas:

1. Entender o poder das oportunidades da web 2.0;

2. Aprender as principais ferramentas da web 2.0 e biblioteca 2.0;

3. Saber combinar recursos eletrônicos e impressos;

4. Ser independente de dispositivo, usar e entregar tudo para laptop, PDA`s e até ipods;

5. Desenvolver marcadores de buscas federadas e adota padrões de URL aberta;

6. Não recear em usar a catalogação e a classificação não-tradicionais e taggings (marcadores), nuvem de taggings, folksonomias, descritores de conteúdo voltados para o usuário e classificações onde for apropriado;

7. "Abraçar" a informação não textual e o poder das imagens, imagens em movimento, sinais e som;

8. Ver o potencial de uso de fontes de conteúdo como o Google Books e Open WorldCat;

9. Usar e desenvolver redes sociais em benefício da empresa;

10. Conectar os usuários com especialistas para discussões, conversas, comunidades de prática e participa delas também;

11. Conectar-se com os usuários, tendo várias ferramentas de comunicação como opção: telefone, skype, referência virtual, mensagem instantânea, SMS, texto manuscrito, correio eletrônico, entre outros.

Peltier-Davis (2009) relaciona uma lista de quatorze competências tanto pessoais como profissionais para se tornar um bibliotecário 2.0:

1. Ter a capacidade de aprender constantemente e rapidamente;

2. Monitorar novas formas de organização e acesso a recursos; 
3. Acompanhar as tendências em tecnologia;

4. Possuir o temperamento de trabalhar independentemente, assim como trabalhar em equipe;

5. Ter a propensão para assumir riscos e trabalhar sob pressão;

6. O serviço deve ser orientado ao usuário;

7. Ser hábil a possibilitar e promover a mudança;

8. Ter senso de humor (mais importante, segundo o autor);

9. Ser comprometido com a continuidade da educação formal e informal;

10. Realizar pesquisas e publicar os resultados;

11. Ler a literatura profissional, principalmente fora da sua área;

12. Torna-se ativo e, em alguns casos, totalmente envolvido no design e nos estudos de usabilidade dos sistemas de informação;

13. Continuar a cooperação e colaboração entre a comunidade global de bibliotecários;

14. Torne-se um defensor da profissão, fazendo o marketing do valor da web 2.0, biblioteca 2.0, e do bibliotecário 2.0 para os tomadores de decisão.

O Conselho Australiano de Aprendizagem e Ensino (Australian Learning and Teaching Council) implementou um projeto para identificar as competências chaves, conhecimentos e atributos requeridos ao bibliotecário 2.0. Foram realizados vários encontros em forma de grupo focal. Os resultados do projeto constataram que o bibliotecário 2.0 está mais relacionado com a qualidade das competências transferíveis e habilidades interpessoais do que a tecnologia propriamente dita (PARTRIDGE; LEE; MUNRO, 2010).

\section{Biblioteca 2.0}

Com a eminência da web 2.0, surgiram a partir de 2005 estudos internacionais relacionando a web 2.0 à Biblioteconomia e a Ciência da informação. Em 2006 os estudos ampliaram e se multiplicaram em 2007 (BLATTMANN; SILVA, 2007).

O termo biblioteca 2.0 apareceu pela primeira vez no blog LibraryCrunch de Michael Basey, em 2005 (MANESS, 2006). 
O tema web 2.0 é dominante nas bibliotecas de hoje. As bibliotecas que utilizam as ferramentas da web 2.0 são chamadas de bibliotecas 2.0. Houve uma evolução e desenvolvimento dessas ferramentas em bibliotecas com o objetivo de construir um ambiente web mais centrado no usuário, que não só fornece conteúdo, mas também busca conteúdos dos próprios usuários, promovendo o engajamento, participação e a colaboração (BREEDING, 2007).

A Biblioteca 2.0 também tenta explorar as habilidades do usuário no projeto e implementação de novos serviços através do encorajamento do feedback e da participação. Os defensores da Biblioteca 2.0 chamam de "radical trust" (confiança radical) a relação entre os usuários e a biblioteca de maneira bem sucedida. Os pesquisadores dessa área previram que o modelo de Biblioteca 2.0 acabaria por substituir o modelo da biblioteca tradicional, onde as ofertas de serviços são unidirecionais e têm caracterizado as bibliotecas durante séculos (PELTIER-DAVIS, 2009).

O cenário atual se caracteriza por usuários diversos e auto-suficientes, que 41 utilizam muitos recursos sem fio, como laptops, celulares, pagers e agora os tablets, Esses usuários enviam massivamente e-mails, mensagens instantâneas, e utilizam redes sociais, blogs, microblogs, wikis, jogos e também fazem muitas compras on line.

Contudo, o que mais surpreende no perfil dos novos usuários é o fato deles estarem cada vez mais satisfeitos com a qualidade da informação que eles encontram na internet. Dessa forma, percebe-se que os usuários diminuíram o uso dos recursos da biblioteca para desenvolver suas pesquisas. A questão não é o acesso ao recurso físico da biblioteca, ou o fato de ir até ela, mas até que ponto a Internet é utilizada adequadamente para busca, recuperação ou comunicação da informação. Segundo Margaix Arnal (2007) a Biblioteca 2.0 teria essa estrutura (Fig. 3): 


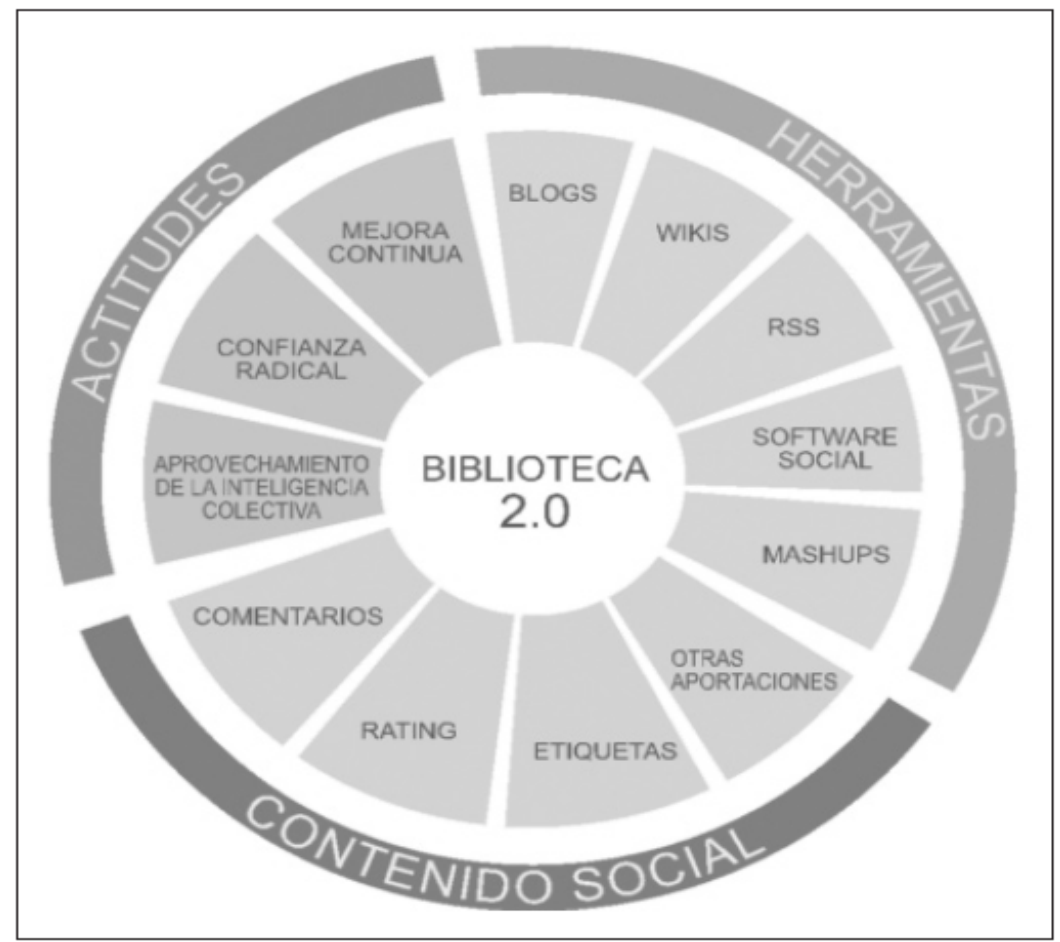

Figura 1: Elementos básicos da biblioteca 2.0.

Fonte: Margaix Arnal (2007)

Nesta estrutura (Fig. 3) as bibliotecas devem utilizar as ferramentas da web 2.0 como os blogs e wikis para divulgar os seus serviços e manter contato com os seus usuários. Contudo, as bibliotecas além da divulgação, devem ao mesmo tempo, ter atitude e interagir através do conteúdo social, com seus usuários e contar com a colaboração deles.

Para Maness (2006) uma teoria para a biblioteca 2.0 poderia ser dividida em quatro elementos essenciais:

a. É centrada no usuário: os usuários participam da criação de produtos e serviços das bibliotecas;

b. Oferece experiência multimídia: por meio de coleções e serviços que contém áudio e vídeo;

c. É socialmente rica: oferece várias formas de comunicação tanto síncrona (ex. mensagem instantânea) e assíncrona (ex.: wikis);

d. É comumente inovadora: permite que os usuários participem das mudanças da biblioteca e que esta mude constantemente na mesma medida. 
A coleção de uma biblioteca 2.0 inclui uma mistura de materiais tradicionais (livros impressos, periódicos, áudio-visual) e formatos emergentes (ebooks, e-folhetins, e-newspapers, e-dissertações, recursos da Internet, objetos digitais, streamings de áudio e vídeo, dispositivos de leitura móvel). Os catálogos de bibliotecas podem permitir o acesso integrado a estes formatos tradicionais e emergentes por meio da próxima geração de catálogos acessíveis ao público (PELTIER-DAVIS, 2009).

As tecnologias da web 2.0 podem ser facilmente integradas aos serviços de bibliotecas existentes, e oferecidos através do portal da biblioteca. Entre os benefícios imediatos para oferecer esse tipo de serviço e, que melhoram a experiência do usuário da biblioteca encontra-se (PELTIER-DAVIS, 2009):

a. Serviços proativos: uso de ferramentas como blogs, wikis, feeds RSS, podcasts (do iTunes da Apple), vídeos (em YouTube), compartilhamento de fotos no Flickr, e mensagens instantâneas via Meebo e Twitter.

b. Melhoria da comunicação (interna e externa): ferramentas de redes sociais, não só melhoram a comunicação de uma biblioteca (externa) com seus usuários, mas também melhoram a comunicação interna e o compartilhamento de conhecimentos.

c. Implementação imediata: Colocar o conteúdo na web não é mais o direito exclusivo de especialistas com conhecimento de HTML e linguagens de programação web. Qualquer um pode adicionar conteúdo online devido à facilidade de criação de blogs, wikis, podcasts, videocasts e perfis em redes sociais.

d. Sobrevivência: Os bibliotecários devem acompanhar o desenvolvimento da web 2.0. Caso estes profissionais hesitem, outros serviços de informação rivais irão fazer o trabalho. Por exemplo, o Google Book Search (http://books.google.com), que fornece acesso ao texto integral ou parcial de livros, tem digitalizado e armazenado em um banco de dados digital contendo vários livros de diversas áreas.

\section{Web 2.0}

O termo web 2.0 foi popularizado por O'Reilly, pioneiro da web e vicepresidente da O'Reilly, em 2005 para uma conferência entre a O'Reilly e a MediaLive International Dale Doughherty, (O'REILLY, 2005). Holmberg et al (2008) constata que 
na literatura o termo possui diversos e contraditórios significados e implicações, podese observar que esse termo pode significar ao mesmo tempo: ideias, tecnologias, culturas, ideais e padrões de comportamento.

Como resultado de brainstorming (tempestade de ideias) inicial da conferência entre O'Reilly e a MediaLive International Dale Doughherty, foi formulado a ideia de web 2.0 através de exemplos (O'REILLY, 2005):

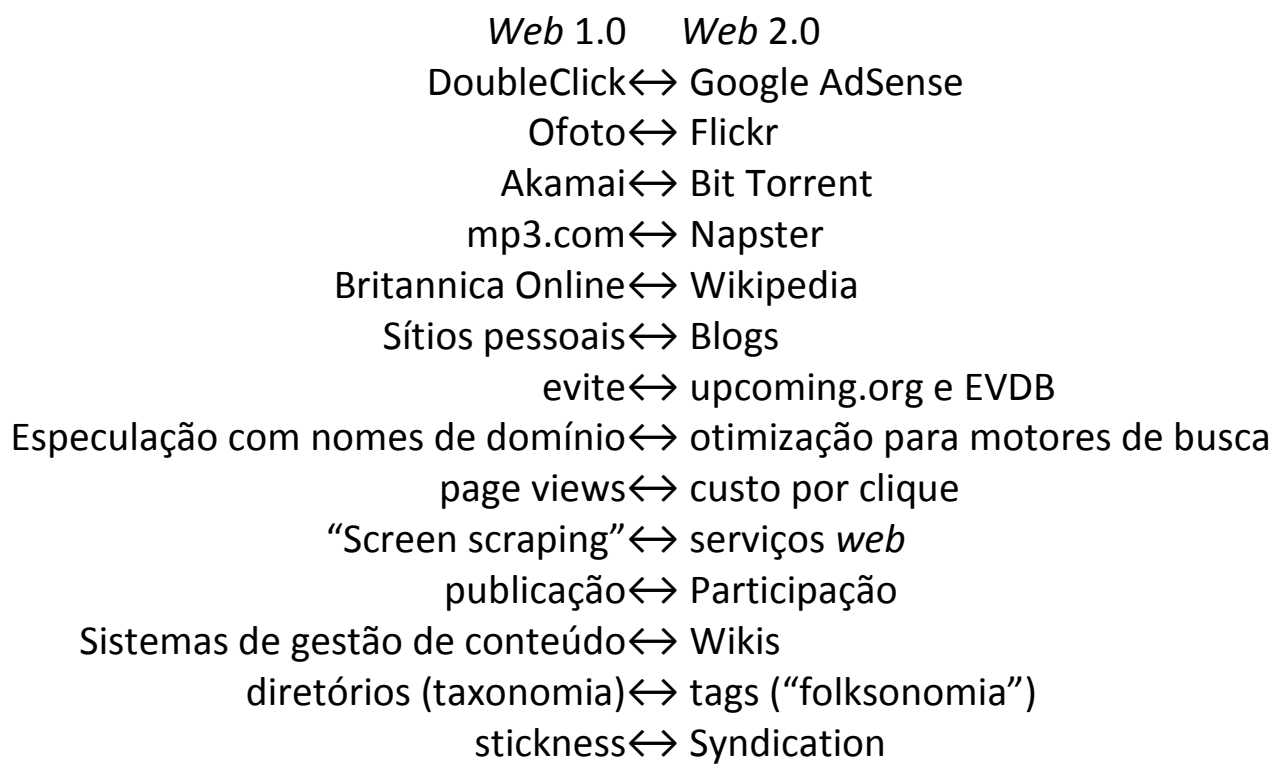

Figura 2: Brainstorming sobre a web 2.0.

Tradução de: O’Reilly (2005).

O criador da World Wide Web, Tim Berners-Lee, afirma que a web 1.0 foi criada para conectar pessoas, ela foi um espaço de interação entre pessoas, e para ele a web 2.0 é um jargão (BERNERS-LEE, 2006). Pode-se constatar uma diferença eminente entre web 1.0 e web 2.0: a velocidade e o número de usuários (NESTA; MI, 2010). Segundo o Site Internet World Stats ${ }^{2}$ que utiliza os dados da Nielsen Online, da International Telecommunications Union, e da $G f K^{3}$, atualmente são 1.966.514.816 usuários até junho de 2010.

\footnotetext{
${ }^{2}$ INTERNET WORLD STATS. Disponível em: www.internetworldstats.com/stats.htm. Acessado em: 17 fevereiro 2011.

${ }^{3}$ Nielsen Online, International Telecommunications Union e GfK são empresas que oferecem serviços de informação e consultoria fornecendo uma compreensão dos consumidores para a tomada de decisão das empresas.
} 
Verifica-se, no dia a dia, que o contexto da web mudou bastante nos últimos anos,

[...] antes de 2004 a web era limitada a alguns usuários de classe média americana e européia. Hoje a web é global, barata e baseada no mercado de comunicação de massa, aplicação web para celulares, serviços sem fio e outra dimensão de conveniência: a web não está apenas disponível, ela te acompanha sempre (NESTA, 2010, p.86).

A web 2.0 é caracterizada pela "mudança da internet como plataforma" (O`REILLY, 2005), passando a ser uma maneira de interação entre pessoas mais barata, eficaz e rápida.

A principal característica da web 2.0 é a interatividade, clica-se e têm resultados, envia-se um e-mail e já se obtém uma resposta. A web 2.0 é conversação, rede interpessoal, customização e individualismo. O foco no conteúdo do contexto das pessoas, locais de trabalho, mercados, comunidades, e aprendizagem. No contexto das bibliotecas isso também é relevante não apenas para os usuários dos portais da web, mas também através da intranet proporcionando maior interação no espaço de trabalho (ABRAM, 2008).

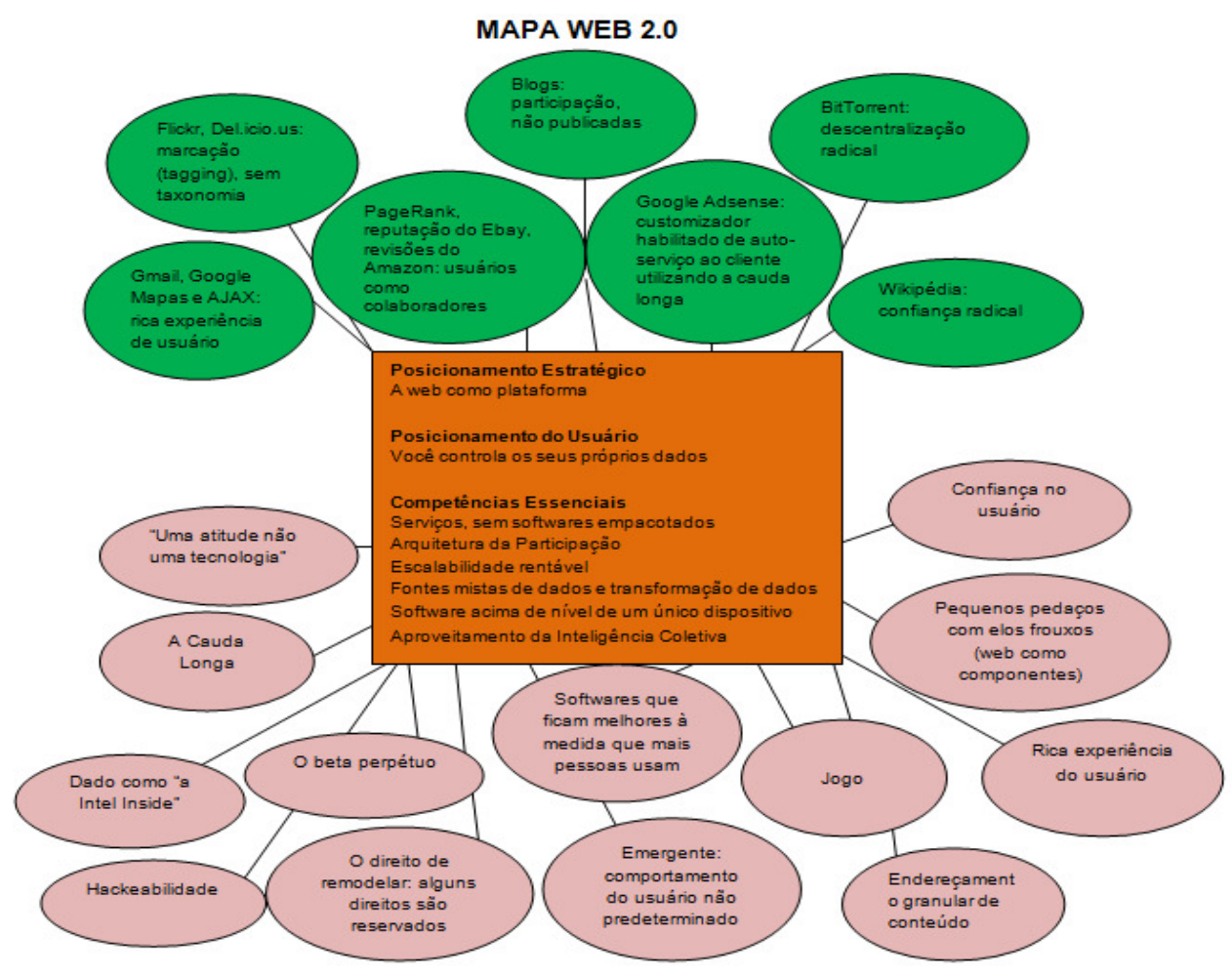

Figura 3: Estrutura da Web 2.0.

Tradução de: O’Reilly (2005). 
A estrutura da web 2.0 (Fig. 2) se divide em três partes, armazenadas em nuvens. Na parte central estão as competências essenciais, na parte inferior a interação dos usuários e na parte superior as ferramentas da web 2.0.

A incorporação de tecnologias da Web 2.0 é comum pela maioria dos sites de relacionamento como: YouTube, Orkut, Delicious, Facebook, MySpace, Second Life, LibraryThing, Flickr, Twitter, WorldCat.org, e outros.

As principais ferramentas que servem como base da Web 2.0 para a interatividade são as seguintes:
a) Blogs
b) Wikis
c) RSS (Really Simple Syndication), feeds
d) Mensagens instantâneas
e) Podcasts e videocasts
f) Folksonomias, marcação (tagging), e nuvens de tags
g) Social bookmarking
h) Sites de redes sociais
i) Mashups
j) Streaming de áudio e vídeo
k) Comunidade de serviços ou compartilhamento de fotos

\section{Considerações Finais}

As tecnologias da informação e comunicação estão cada vez mais presentes nas atividades cotidianas. Os profissionais que lidam com a informação se vêem diante de um desafio na sociedade em rede, principalmente com a evolução da web 1.0 para web 2, estando o usuário mais autônomo e perdido no mundo de possibilidades de comunicação e compartilhamento da informação. Os bibliotecários estão buscando se adaptar as mudanças recorrentes das novas tecnologias de informação, usando as ferramentas da web 2.0 nas bibliotecas, o que se pode chamar de biblioteca 2.0.

Além disso, o perfil de profissional também está em mudança, o chamado bibliotecário 2.0 é aquele que possui habilidades e competências para interagir com os 
novos usuários e sabe lidar com as novas ferramentas da web 2.0. Vários autores caracterizaram o bibliotecário 2.0 e, dentre essas características, pode-se destacar as seguintes: o profissional tem que saber manusear as ferramentas da web 2.0 e da biblioteca 2.0; ser rápido na tomada de decisões; maior interação com os usuários; acompanhar as novas tendências tecnológicas, mas não apenas pelo fato do modismo, testar e verificar a real usabilidade da ferramenta para melhorar os produtos e serviços da unidade de informação e ter compromisso com a educação continuada.

É necessário que os bibliotecários fiquem atentos e estejam preparados para implementar as novas tecnologias da informação e comunicação da web 2.0, antes que outras novidades provoquem mudanças radicais uma vez que a tecnologia está sempre em evolução.

\section{Referências}

ABRAM, Stephen. Social libraries: the Librarian 2.0 phenomenon. Library Resources \& Technical Services, vol. 52, no. 2, pp. 19-22, 2008.

BERNERS-LEE, Tim. Transcript of an interview recorded in 2006. Disponível em: < http://www.ibm.com/developerworks/podcast/dwi/cm-int082206.txt> Acessado em: 16 fevereiro 2011.

BLATTMANN, Ursula; SILVA, Fabiano Couto Corrêa da. Colaboração e interação na web 2.0 e a biblioteca 2.0. Revista ABC: Biblioteconomia em Santa Catarina, Florianópolis, v. 12, n. 2, p.191-125, jul/dez., 2007. Disponível em: http://revista.acbsc.org.br/index.php/racb/article/viewArticle/530. Acessado em: 4 janeiro 2011.

BREEDING, Marshall. We need to go beyond web 2.0. Computers in libraries. V.27, n. 5, p.22-25, maio, 2007. Disponível em: http://www.librarytechnology.org/ltgdisplaytext.pl?RC=12574 . Acessado em: 4 janeiro 2011.

BRITO, Jorgivânia Lopes; SILVA, Patrícia Maria. A biblioteca 2.0 e suas ferramentas de colaboração e interação: como aplicá-las no fazer bibliotecário? Biblionline, João Pessoa, v. 6, n. 1, $2010 . \quad$ Disponível em: http://periodicos.ufpb.br/ojs2/index.php/biblio/article/view/4910/3715 . Acessado em: 10 janeiro 2011.

CASTELLS, Manuel. A sociedade em rede. 8.ed. São Paulo: Paz e Terra, 2005. 
COHEN, Laura. A librarian's 2.0 manifesto. Disponível em: http://liblogs.albany.edu/library20/2006/11/a librarians 20 manifesto.html Acessado em: 4 janeiro 2011.

F/NAZCA S\&S. Radar. Disponível em: http://www.fnazca.com.br/wpcontent/uploads/2010/11/fradar-7.pdf Acessado em: 16 fevereiro 2011.

HOLMBERG, KIM; ET AL. What is library 2.0?.Journal of Documentation, v.65, n.4, p.668-681. Disponível: <http: //www.emeraldinsight.com/0022-0418.htm>. Acessado em: 16 fevereiro 2011.

KING, David Lee. Am I a 2.0 librarian - and the library 2.0 spectrum. One-Person Library, v.24, n.9, p7-7, 3/4p, jan 2008. Disponível em: http://search.ebscohost.com.ez53.periodicos.capes.gov.br/login.aspx?direct=true\&db =lih\&AN=28514125\&lang=pt-br\&site=ehost-live . Acessado em: 16 fevereiro 2011.

LÉVY, Pierre. Cibercultura. 2. ed. Tradução de Carlos Irineu da Costa. São Paulo: Ed. 34, 2000.

LINHAUS, Maikon; OLIVEIRA, Elias de. A biblioteca na cultura digital: tendências e perspectivas visando um ambiente mais interativo. SNBU, 2010 (apresentação oral). Disponível em: http://www.snbu,2010. com.br/documentos/apresentacao oral.pdf

MANESS, Jack M. Library 2.0 theory: web 2.0 and its implications for libraries. Webology, v.3, n.2, jul., $2006 . \quad$ Disponível em: http://www.webology.ir/2006/v3n2/a25.html . Acessado em: 7 janeiro 2011.

MARGAIX ARNAL, Dídac. Conceptos de web 2.0 y biblioteca 2.0: origen, definiciones y retos para las bibliotecas actuales. El profesional de la información, v.16, n. 2, marzoabril, $2007 . \quad$ Disponivel em: www.elprofessionaldelainformacion.com/contenidos/2007/marzo/02.pdf . Acessado em: 4 janeiro 2011.

NESTA, Frederick; MI, Jia. Library 2.0 or library III: returning to leadership. Library Management, v.32, n. 1/2, 2011. Disponível em: www.emeraldinsight.com/01435124.htm> Acessado em: 16 fevereiro 2011.

O'REILLY, Tim. What is web 2.0. Disponível em: http://oreilly.com/web2/archive/what-is-web-20.html\#mememap . Acessado em: 4 janeiro 2011.

PARTRIDGE, Helen; LEE, Julie; MUNRO, Carrie. Becoming "librarian 2.0": the skills, knowledge, and attributes required by library and information science professionals in a web 2.0 world (and beyond). Library Trends, v.59, n.1-2, p.315-335, summer 2010/fall 2010. 
PELTIER-DAVIS, Cheryl. Web 2.0, library 2.0, library user 2.0, librarian 2.0: innovative services for sustainable libraries. Computers in Libraries, vol. 29, no. 10, p. 16-21, NovDec, 2009.

RIBEIRO, Nuno Magalhães, ET AL. Informáticas e competências tecnológicas para a sociedade da informação. 2.ed. Porto: Universidade Fernando Pessoa, c2005.

SANTOS, Plácido L. V. Amorim. Capítulo 5: as novas tecnologias na formação do profissional da informação. IN: VALENTIM, Marta Lígia (Org.). Formação do profissional da informação. São Paulo: Polis, 2002. pg. 103-116.

SILVA, Fabiano Couto Corrêa da. Bibliotecários especialistas: guia de especialidades e recursos informacionais. Brasília: Thesaurus, 2005.

SIQUEIRA, Ethevaldo. Para compreender o mundo digital. São Paulo: Globo, 2008.

STEPHENS, Michael. Sharpen these skills for librarian 2.0. One-Person Library, v. 24, n. 9, p8-9, jan $2008 . \quad$ Disponível: http://search.ebscohost.com/login.aspx?direct=true\&db=lih\&AN=28514127\&lang=ptbr\&site=ehost-live. Acessado em: 17 fevereiro 2011. 